\title{
An Academic Research Coach: An Innovative Approach to Increasing Scholarly Productivity in Medicine
}

\author{
Christy M McKinney, PhD, MPH ${ }^{*}$; Somnath Mookherjee, MD²; Stephan D Fihn, MD, MPH²; Thomas H Gallagher, MD²
}

'Department of Pediatrics, Division of Craniofacial Medicine and Seattle Children's Research Institute, University of Washington, Seattle, Washington; ${ }^{2}$ Department of Medicine, Division of General Internal Medicine, University of Washington, Seattle, Washington.

BACKGROUND: Academic faculty who devote most of their time to clinical work often struggle to engage in meaningful scholarly work. They may be disadvantaged by limited research training and limited time. Simply providing senior mentors and biostatistical support has limited effectiveness.

OBJECTIVE: We aimed to increase productivity in scholarly work of hospitalists and internal medicine physicians by integrating an Academic Research Coach into a robust faculty development program.

DESIGN: This was a pre-post quality improvement evaluation.

SETTING: This was conducted at the University of Washington in faculty across three academic-affiliated hospitals and 10 academic-affiliated clinics.

PARTICIPANTS: Participants were hospitalists and internists on faculty in the Division of General Internal Medicine at the University of Washington.

INTERVENTION: The coach was a 0.50 full time equivalent health services researcher with strong research methods, project implementation, and interpersonal skills. The coach consulted on research, quality improvement, and other scholarship.

MEASUREMENTS: We assessed the number of faculty supported, types of services provided, and numbers of grants, papers, and abstracts submitted and accepted.

RESULTS: The coach consulted with 49 general internal medicine faculty including 30 hospitalists who conducted 63 projects. The coach supported 13 publications, 11 abstracts, four grant submissions, and seven manuscript reviews. Fortyeight faculty in other departments benefited as co-authors.

CONCLUSION: Employing a dedicated health services researcher as part of a faculty development program is an effective way to engage clinically oriented faculty in meaningful scholarship. Key aspects of the program included an accessible and knowledgeable coach and an ongoing marketing strategy. Journal of Hospital Medicine 2019;14:457-461. Published online first April 8, 2019. (C) 2019 Society of Hospital Medicine

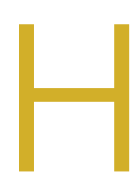

istorically, academic medicine faculty were predominantly physician-scientists. ${ }^{1}$ During the past decade, the number of clinician-educators and nontenured clinicians has grown. ${ }^{2}$ Many academically oriented clinical faculty at our institution would like to participate in and learn how to conduct quality scholarship. While institutional requirements vary, scholarly work is often required for promotion, ${ }^{3}$ and faculty may also desire to support the scholarly work of residents. Moreover, a core program component of the Accreditation Council of Graduate Medical Education standards requires faculty to "maintain an environment of inquiry and scholarship with an active research component. ${ }^{\prime 4}$ Yet clinical faculty often find academic projects to be challenging. Similar to residents, clinical academic faculty frequently lack formal

*Corresponding Author: Christy M. McKinney, PhD, MPH; E-mail: christy. mckinney@seattlechildrens.org; Telephone: 206-884-0584.

Find Additional Supporting Information in the online version of this article.

Received: November 14, 2018; Revised: February 20, 2019;

Accepted: February 20, 2019

๑ 2019 Society of Hospital Medicine DOI 10.12788/jhm.3194 training in health services research or quality improvement science, have insufficient mentorship, and typically have limited uncommitted time and resources. ${ }^{5}$

One approach to this problem has been to pair junior clinicians with traditional physician scientists as mentors. ${ }^{6,7}$ This type of mentorship for clinical faculty is increasingly difficult to access because of growing pressure on physician-scientist faculty to conduct their own research, seek extramural funding, meet clinical expectations, and mentor fellows and faculty in their own disciplines. ${ }^{8}$ Moreover, senior research faculty may not be prepared or have the time to teach junior faculty how to deal with common stumbling blocks (eg, institutional review board [IRB] applications, statistically testable hypothesis development, and statistical analysis). 8.9 Seminars or works-in-progress sessions are another strategy to bolster scholarly work, but the experience at our institution is that such sessions are often not relevant at the time of delivery and can be intimidating to clinical faculty who lack extensive knowledge about research methods and prior research experience.

Another approach to supporting the research efforts of academic clinicians is to fund a consulting statistician. However, without sufficient content expertise, statisticians may 
be frustrated in their efforts to assist clinicians who struggle to formulate a testable question or to work directly with data collected. Statisticians may be inexperienced in writing IRB applications or implementing protocols in a clinical or educational setting. Furthermore, statistical consultations are often limited in scope ${ }^{10}$ and, in our setting, rarely produce a durable improvement in the research skills of the faculty member or the enduring partnership required to complete a longer-term project. Because of these shortcomings, we have found that purely statistical support resources are often underutilized and ineffective.

Other models to facilitate scholarship have been employed, but few focus on facilitating scholarship of clinical faculty. One strategy involved supporting hospitalist's academic productivity by reducing hospitalists' full-time equivalent (FTE) and providing mentorship. ${ }^{11}$ For many, this approach is likely cost-prohibitive. Others have focused primarily on resident and fellow scholarships. ${ }^{5,6}$

In this report, we describe an educational innovation to educate and support the scholarly work of academic hospitalists and internists by using an academic research coach. We recruited a health researcher with extensive experience in research methods and strong interpersonal skills with the ability to explain and teach research concepts in an accessible manner. We sought an individual who would provide high-yield single consultations, join project teams to provide ongoing mentorship from conception to completion, and consequently, bolster scholarly productivity and learning among nonresearch clinicians in our Division. We anticipated that providing support for multiple aspects of a project would be more likely to help faculty overcome barriers to research and disseminate their project results as scholarly output.

\section{METHODS}

The coach initiative was implemented in the Division of General Internal Medicine at the University of Washington. The Division has over 200 members (60 hospitalists), including clinical instructors and acting instructors, who have not yet been appointed to the regular faculty (clinician-educators and physician scientists), and full-time clinical faculty. Division members staff clinical services at four area hospitals and 10 affiliated internal medicine and specialty clinics. Eligible clients were all Division members, although the focus of the initial program targeted hospitalists at our three primary teaching hospitals. Fellows, residents, students, and faculty from within and outside the Division were welcome to participate in a project involving coaching as long as a Division faculty member was engaged in the project.

\section{Program Description}

The overall goal of the coach initiative was to support the scholarly work of primarily clinical Division members. Given our focus was on clinical faculty with little training on research methodology, we did not expect the coach to secure grant funding for the position. Instead, we aimed to increase the quality and quantity of scholarship through publications, ab- stracts, and small grants. We defined scholarly work broadly: clinical research, quality improvement, medical education research, and other forms of scientific inquiry or synthesis. The coach was established as a 0.50 FTE position with a 12-month annually renewable appointment. The role was deemed that of a coach instead of a mentor because the coach was available to all Division members and involved task-oriented consultations with check-ins to facilitate projects, rather than a deeper more developmental relationship that typically exists with mentoring. The Division leadership identified support for scholarly activity as a high priority and mentorship as an unmet need based on faculty feedback. Clinical revenue supported the position.

Necessary qualifications, determined prior to hiring, included a PhD in health services or related field (eg, epidemiology) or a master's degree with five years of experience in project management, clinical research, and study design. The position also called for expertise in articulating research questions, selecting study designs, navigating the IRB approval process, collecting/managing data, analyzing statistics, and mentoring and teaching clinical faculty in their scholarly endeavors. A track record in generating academic output (manuscripts and abstracts at regional/national meetings) was required. We circulated a description of the position to Division faculty and to leadership in our School of Public Health.

Based on these criteria, an inaugural coach was hired (author C.M.M.). The coach had a PhD in epidemiology, 10 years of research experience, 16 publications, and had recently finished a National Institutes of Health (NIH) career development award. At the time of hiring, she was a Clinical Assistant Professor in the School of Dentistry, which provided additional FTE. She had no extramural funding but was applying for $\mathrm{NIH}$-level grants and had received several small grants.

To ensure uptake of the coach's services, we realized that it was necessary to delineate the scope of services available, clarify availability of the coach, and define expectations regarding authorship. We used an iterative process that took into consideration the coach's expertise, services most needed by the Division's clinicians, and discussions with Division leadership and faculty at faculty meetings across hospitals and clinics. A range of services and authorship expectations were defined. Consensus was reached that the coach should be invited to coauthor projects where design, analysis, and/ or substantial intellectual content was provided and for which authorship criteria were met. ${ }^{12}$ Collegial reviews by the coach of already developed manuscripts and time-limited, low-intensity consultations that did not involve substantial intellectual contributions did not warrant authorship. ${ }^{12}$ On this basis, we created and distributed a flyer to publicize these guidelines and invite Division members to contact the coach (Figure 1).

The coach attended Division, section, and clinical group meetings to publicize the initiative. The coach also individually met with faculty throughout the Division, explained her role, described services available, and answered questions. The marketing effort was continuous and calibrated with more or less exposure depending on existing projects and the coach's 


\section{Academic Research Coach \\ Services and Consultations}

\section{Who is the Coach?}

\{Name\} is a PhD epidemiologist with 10 years' experience designing, conducting, and publishing clinical research. She is here to help you.

\section{Why use the Coach?}

The Academic Research Coach (ARC) is here to facilitate success in your scholarly activities. The ARC can help elevate methodological, statistical and research implementation aspects of your projects.

\section{Consultations}

Who can use the $A R C$ ? Faculty in the Division of General Internal Medicine at UWMC, Harborview, and the VA.

Consultations.

- One-hour initial consults are encouraged.

- For new and ongoing projects, an informal half-page summary of the project idea or status, and a description of assistance needed will be requested prior to the consult.

- Ongoing consults for different phases of the same project are encouraged.

- In-depth support involving more than several hours of support for a given phase requires prior approval.

- Authorship. Because the ARC typically provides intellectual contributions to projects, it is expected that the ARC be listed as a coauthor on products when appropriate.

\section{Services Offered}

Study Design

- Study design and project development

- Developing a testable research hypothesis

- Quality improvement and research studies Institutional Review Board (IRB)

- Determining if IRB review is needed

- Identification of the right forms

- Review of applications and modifications

Study Infrastructure \& Support

- Input into developing study protocols

- Facilitate getting student/volunteer help Data Collection

- Input on surveys and data collection tools

- REDCap database support - REDCap is a tool that facilitates data entry of data collected from study participants (eg, survey)

Statistical Analysis

- Assist with statistical analysis plan

- Basic power calculations

- Guide biostatistics consultations

- Guide data cleaning for statistical analysis

- Conduct statistical analyses*

Products: Abstracts, Posters, Presentations, Manuscripts

- Provide review and input

- Particular focus on methods section

Resource identification and Support

- Identify training opportunities

- Field requests for small research resources*

- Software, Amalga datasets, etc.

*These services require prior approval by GIM Leadership.

\section{Contact Information:}

[Name / Address or ARC]

FIG 1. Academic Research Coach Services and Consultations

availability. In addition, the coach coordinated with the director of the Division's faculty development program to cohost worksin-progress seminars, identify coach clients to present at these meetings, and provide brief presentations on a basic research skill at meetings. Faculty built rapport with the coach through these activities and became more comfortable reaching out for assistance. Because of the large size of the Division, it was decided to roll out the initiative in a stepwise fashion, starting with hospitalists before expanding to the rest of the Division.

Most faculty contacted the coach by e-mail to request a consultation, at which time the coach requested that they complete a preconsultation handout (Figure 2). Initial coaching appointments lasted one hour and were in-person. Coaching entailed an in-depth analysis of the project plan and advice on how to move the project forward. The coach provided tailored scholarly project advice and expertise in research methods. After initial consultations, she would review grant proposals, IRB applications, manuscripts, case report forms, abstracts,

\section{Project Title \\ title / brief title description of what you are doing}

Investigators, collaborators, authors

names and roles/expertise

\section{Deliverables}

(eg, journal articles [target journal, word limit], conference poster/presentation, preliminary data for grant)

Significance, Rationale, Background

Aims and Hypotheses

- General Aim

- Hypotheses, primary and secondary

\section{Methods}

Study Design

- Study Design: examples - cohort, cross-sectional study, pre-/post, unsure

Study Populations(s)

- Source population: clinic, time period, participants (eg, patients, providers), age, sex, condition

- Inclusions and exclusions

Data Collection

- How you will collect your data: survey, electronic, chart review

- Conceptual framework needed?

- Variables you want to collect data on, concepts that are important

Analysis and Tables

- Number of participants anticipated, if known

- What do you want to show/report

- Type of analysis you want to do, if known (eg, ttest, descriptive, statistical model, unsure) Anticipated issues/challenges

- Key data you don't have but should, missing data

- Timing of data collection, lack of comparison, access to data, other, funds to do work Institutional Review Board

- Do you need IRB? Is it research, quality/improvement, unsure?

- What IRBs are involved and what IRB forms (research, exempt, minimal risk, full review, unsure)

Funding and Timeline

- Cost and funds available, if any

- Brief summary of expected timeline

FIG 2. Project Planner

and other products. Her efforts typically focused on improving the methods and scientific and technical writing. Assistance with statistical analysis was provided on a case-by-case basis to maintain broad availability. To address statistically complex questions, the coach had five hours of monthly access to a PhD biostatistician via an on-campus consulting service. Follow-up appointments were encouraged and provided as needed by e-mail, phone, or in-person. The coach conducted regular reach outs to facilitate projects. However, execution of the research was generally the responsibility of the faculty member.

\section{Program Evaluation}

To characterize the reach and scope of the program, the coach tracked the number of faculty supported, types of services provided, status of initiated projects, numbers of grants generated, and the dissemination of scholarly products including papers and abstracts. We used these metrics to create summary reports to identify successes and areas for improvement. Monthly meetings between the coach and Division leadership were used to fine-tune the approach. 
We surveyed coach clients anonymously to assess their satisfaction with the coach initiative. Using Likert scale questions where 1 = completely disagree and $5=$ completely agree, we asked (1) if they would recommend the coach to colleagues, (2) if their work was higher quality because of the coach, (3) if they were overall satisfied with the coach, (4) whether the Division should continue to support the coach, and (5) if the coach's lack of clinical training negatively affected their experience. This work was considered a quality improvement initiative for which IRB approval was not required.

\section{RESULTS}

Over 18 months, the coach supported a 49 Division members including 30 hospitalists and 63 projects. Projects included a wide range of scholarship: medical education research, qualitative research, clinical quality improvement projects, observational studies, and a randomized clinical trial. Many clients ( $n=16$ ) used the coach for more than one project. The scope of work included limited support projects (identifying research resource and brainstorming project feasibility) lasting one to two sessions ( $n=25$ ), projects with a limited scope (collegial reviews of manuscripts and assistance with IRB submissions) but requiring more than two consultations ( $n=24)$, and ongoing in-depth support projects (contributions on design, data collection, analysis, and manuscript writing) that required three consultations or more $(n=14)$. The majority of Division members (75\%) supported did not have master's level training in a health services-related area, six had NIH or other national-level funding, and two had small grants funded by local sources prior to providing support. The number of Division faculty on a given project ranged from one to four.

The coach directly supported 13 manuscripts with coach authorship, seven manuscripts without authorship, 11 abstracts, and four grant submissions (Appendix). The coach was a coauthor on all the abstracts and a coinvestigator on the grant applications. Of the 13 publications the coach coauthored, 11 publications have been accepted to peer-reviewed journals and two are currently in the submission process. The types of articles published included one medical evaluation report, one qualitative study, one randomized clinical trial, three quality assessment/improvement reports, and five epidemiologic studies. The types of abstracts included one qualitative report, one systematic review, one randomized clinical trial, two quality improvement projects, two epidemiologic studies, and four medical education projects. Three of four small grants submitted to local and national funders were funded.

The coach's influence extended beyond the Division. Forty-eight university faculty, fellows, or students not affiliated with general internal medicine benefited from coach coaching: 26 were authors on papers and/or abstracts coauthored by the coach, 17 on manuscripts the coach reviewed without authorship, and five participated in consultations.

The coach found the experience rewarding. She enjoyed working on the methodologic aspects of projects and benefited from being included as coauthor on papers.

Twenty-nine of the 43 faculty (67\%) still at the institution re- sponded to the program assessment survey. Faculty strongly agreed that they would recommend the coach to colleagues (average \pm standard deviation [SD]: $4.7 \pm 0.5$ ), that it improved the quality of their work $(4.5 \pm 0.9)$, that they were overall satisfied with the coaching $(4.6 \pm 0.7)$, and that the Division should continue to support the coach $(4.9 \pm 0.4)$. Faculty did not agree that the lack of clinical training of the coach was a barrier $(2.0 \pm 1.3)$.

\section{DISCUSSION}

The coach program was highly utilized, well regarded, and delivered substantial, tangible, and academic output. We anticipate the coach initiative will continue to be a valuable resource for our Division and could prove to be a valuable model for other institutions seeking to bolster the scholarly work of clinical academicians.

Several lessons emerged through the course of this project. First, we realized it is essential to select a coach who is both knowledgeable and approachable. We found that after meeting the coach, many faculty sought her help who otherwise would not have. An explicit, ongoing marketing strategy with regular contact with faculty at meetings was a key to receiving consult requests.

Second, the lack of a clinical background did not seem to hinder the coach's ability to coach clinicians. The coach acknowledged her lack of clinical experience and relied on clients to explain the clinical context of projects. We also learned that the coach's substantial experience with the logistics of research was invaluable. For example, the coach had substantial experience with the IRB process and her pre-reviews of IRB applications made for a short and relatively seamless experience navigating the IRB process. The coach also facilitated collaborations and leveraged existing resources at our institution. For example, for a qualitative research project, the coach helped identify a health services faculty member with this specific expertise, which led to a successful collaboration and publication. Although a more junior coach with less established qualifications may be helpful with research methods and with the research process, our endeavor suggests that having a more highly trained and experienced researcher was extremely valuable. Finally, we learned that for a Division of our size, the 0.50 FTE allotted to the coach is a minimum requirement. The coach spent approximately four hours a week on marketing, attending faculty meetings and conducting brief didactics, two hours per week on administration, and 14 hours per week on consultations. Faculty generally received support soon after their requests, but there were occasional wait times, which may have delayed some projects.

Academic leaders at our institution have noted the success of our coach initiative and have created a demand for coach services. We are exploring funding models that would allow for the expansion of coach services to other departments and divisions. We are in the initial stages of creating an Academic Scholarship Support Core under the supervision of the coach. Within this Core, we envision that various research support services will be triaged to staff with appropriate expertise; for example, a regulatory coordinator would review IRB applications while a mas- 
ter's level statistician would conduct statistical analyses.

We have also transitioned to a new coach and have continued to experience success with the program. Our initial coach (author C.M.M.) obtained an NIH R01, a foundation grant, and took over a summer program that trains dental faculty in clinical research methods leaving insufficient time for coaching. Our new coach also has a PhD in epidemiology with NIH R01 funding but has more available FTE. Both of our coaches are graduates of our School of Public Health and institutions with such schools may have good access to the expertise needed. Nonclinical PhDs are often almost entirely reliant on grants, and some nongrant support is often attractive to these researchers. Additionally, PhDs who are junior or mid-career faculty that have the needed training are relatively affordable, particularly when the resource is made available to large number of faculty. For example, our first coach cost $\$ 48,000$ a year for $50 \%$ FTE.

A limitation to our assessment of the coach initiative was the lack of pre- and postintervention metrics of scholarly productivity. We cannot definitively say that the Division's scholarly output has increased because of the coach. Nevertheless, we are confident that the coach's coaching has enhanced the scholarly work of individual clinicians and provided value to the Division as a whole. The coach program has been a success in our Division. Other institutions facing the challenge of supporting the research efforts of academic clinicians may consider this model as a worthy investment.

Disclosures: The authors have nothing to disclose.

\section{References}

1. Marks AR. Physician-scientist, heal thyself. J Clin Invest. 2007;117(1):2. https:// doi.org/10.1172/JCI31031.

2. Bunton SA, Corrice AM. Trends in tenure for clinical M.D. faculty in U.S. medical schools: a 25-year review. Association of American Medical Colleges: Analysis in Brief. 2010;9(9):1-2; https://www.aamc.org/download/139778/ data/aibvol9_no9.pdf. Accessed March 7, 2019.

3. Bunton SA, Mallon WT. The continued evolution of faculty appointment and tenure policies at U.S. medical schools. Acad Med. 2007;82(3):281-289. https://doi.org/10.1097/ACM.0b013e3180307e87.

4. Accreditation Council for Graduate Medical Education. ACGME Common Program Requirements. 2017; http://www.acgme.org/What-We-Do/Accreditation/Common-Program-Requirements. Accessed March 7, 2019.

5. Penrose LL, Yeomans ER, Praderio C, Prien SD. An incremental approach to improving scholarly activity. J Grad Med Educ. 2012;4(4):496-499. https://doi. org/10.4300/JGME-D-11-00185.1.

6. Manring MM, Panzo JA, Mayerson JL. A framework for improving resident research participation and scholarly output. J Surg Educ. 2014;71(1):8-13. https://doi.org/10.1016/j.jsurg.2013.07.011.

7. Palacio A, Campbell DT, Moore M, Symes S, Tamariz L. Predictors of scholarly success among internal medicine residents. Am J Med. 2013;126(2):181-185. https://doi.org/10.1016/j.amjmed.2012.10.003.

8. Physician-Scientist Workforce Working Group. Physician-scientist workforce (PSW) report 2014. https://report.nih.gov/Workforce/PSW/challenges.aspx. Accessed December 27, 2018.

9. Straus SE, Johnson MO, Marquez C, Feldman MD. Characteristics of successful and failed mentoring relationships: a qualitative study across two academic health centers. Acad Med. 2013;88(1):82-89. https://doi.org/10.1097/ ACM.0b013e31827647a0.

10. Altman DG, Goodman SN, Schroter S. How statistical expertise is used in medical research. JAMA. 2002;287(21):2817-2820. https://doi.org/10.1001/ jama.287.21.2817.

11. Howell E, Kravet S, Kisuule F, Wright SM. An innovative approach to supporting hospitalist physicians towards academic success. J Hosp Med. 2008;3(4):314-318. https://doi.org/10.1002/jhm.327.

12. Kripalani S, Williams MV. Author responsibilities and disclosures at the Journal of Hospital Medicine. J Hosp Med. 2010;5(6):320-322. https://doi. org/10.1002/jhm.715. 